\title{
Recombinant hirudin: kinetic mechanism for the inhibition of human thrombin
}

\author{
Stuart R.Stone ${ }^{1}$ and Jan Hofsteenge \\ Friedrich Miescher-Institut, PO Box 2543, CH-4002 Basel, Switzerland \\ 'To whom correspondence should be addressed
}

Recombinant hirudin variant-2( $\left.\mathrm{Lys}^{47}\right)$, was found to be a competitive inhibitor of human $\alpha$-thrombin with respect to peptidyl p-nitroanilide substrates. These results contrast with those of Degryse and coworkers that suggest that recombinant hirudin variant-2( $\left.\mathrm{Lys}^{47}\right)$ inhibited thrombin by a noncompetitive mechanism [Degryse et al. (1989) Protein Engng, $2,459-465]$. $\gamma$-Thrombin, which can arise from $\alpha$-thrombin by autolysis, was shown to have an affinity for recombinant hirudin variant-2( $\left.\mathrm{Lys}^{47}\right)$ that was four orders of magnitude lower than that of $\alpha$-thrombin. It was demonstrated that the apparent noncompetitive mechanism observed previously was probably caused by a contamination of the thrombin preparation by $\gamma$-thrombin. Comparison of the inhibition of $\alpha$ thrombin by recombinant hirudins variant-2(Lys $\left.{ }^{47}\right)$ and variant-1, which differ from one another in eight out of $\mathbf{6 5}$ amino acids, indicated that the two variants have essentially the same kinetic parameters.

Key words: hirudin/kinetics/thrombin

\section{Introduction}

Hirudin has received attention recently as a potential therapeutic agent for the control of thrombosis (Wallis, 1988). It was originally isolated from the medicinal leech Hirudo medicinalis (Markwardt, 1970) and many different isoforms have been subsequently isolated and sequenced (Bagdy et al., 1976; Dodt et al., 1984, 1986; Tripier, 1988; Scharf et al., 1989). The major form of hirudin (termed variant 1) is a polypeptide of 65 amino acids which contains a single sulphotyrosyl residue. The possibility of using hirudin as a therapeutic agent has evolved with the development of systems for the recombinant expression of hirudin (Bergmann et al., 1986; Fortkamp et al., 1986; Harvey et al., 1986; Meyhack et al., 1987; Loison et al., 1988).

The small size of hirudin has allowed the determination of its tertiary structure by two-dimensional NMR techniques (Clore et al., 1987; Folkers et al., 1989; Haruyama and Wüthrich, 1989). These studies indicate that hirudin is composed of a compact $\mathrm{N}$-terminal domain (residues $3-49$ ) held together by three disulphide bonds, and a disordered $\mathrm{C}$-terminal tail (residues $50-65$ ). The structures of complexes between human $\alpha$-thrombin and two recombinant hirudins have also been determined recently (Rydel et al., 1990; Grütter et al., 1990). These structures indicate that hirudin inhibits thrombin by a novel mechanism. Hirudin binds with its $\mathrm{N}$-terminal three residues in the activesite cleft of thrombin; the hirudin polypeptide chain runs in a direction opposite to that expected for a substrate. In addition, the primary specificity pocket of thrombin is not occupied by hirudin. The C-terminal tail of hirudin wraps around the putative fibrinogen secondary binding site.
The kinetics of inhibition of thrombin by hirudin have been studied by a number of groups and the results obtained are not entirely consistent between studies (Fenton et al., 1979; Walsmann and Markwardt, 1981; Stone and Hofsteenge, 1986; Braun et al., 1988a; Dodt et al., 1988, 1990; Degryse et al., 1989). Although all studies indicate that hirudin is an extremely tight-binding inhibitor of thrombin, estimates of the dissociation constant of the thrombin-hirudin complex have varied by over three orders of magnitude (Walsmann and Markwardt, 1981; Stone and Hofsteenge, 1986). The discrepancies between the various values for the dissociation constants can be explained at least in part by the use of different reaction conditions and different forms of hirudin and thrombin. For example, the dissociation constant for the thrombin-hirudin complex has been shown to be strongly dependent on ionic strength (Stone and Hofsteenge, 1986; Stone et al., 1989). The post-translational modification of Tyr63 to form sulphotyrosine does not occur in any of the expression systems so far used and this lack of a sulphate group leads to a lower affinity of human $\alpha$-thrombin for the recombinant molecule (Braun et al., 1988a; Dodt et al., $1988,1990)$. The affinity of human thrombin for hirudin is higher than that of bovine thrombin (Dodt et al., 1990). Proteolytically degraded forms of human thrombin have a lower affinity for hirudin (Landis et al., 1978; Stone et al., 1987).

Different mechanisms of inhibition have been suggested also by different workers. While the results of Stone and Hofsteenge (1986) indicate that hirudin variant-1 inhibits thrombin by a competitive mechanism, Degryse et al. (1989) have suggested that a noncompetitive mechanism applies to recombinant hirudin variant- 2 with the mutation Asn $47 \rightarrow$ Lys $\left(\right.$ rHV2-Lys ${ }^{471}$ ). This difference in the kinetic mechanism could be due to the different forms of hirudin used or to the different assay conditions in the two studies.

This paper attempts to determine the basis for the observed difference in kinetic mechanism. Moreover, we have determined the kinetic constants for rHV2- $\mathrm{Lys}^{47}$ and recombinant hirudin variant-1 ( $\mathrm{rHV} 1$ ) under identical conditions and, thus, have been able to evaluate to what extent the previous discrepancies in values of dissociation constants were due to differences in forms of hirudin used.

\section{Materials and methods}

\section{Materials}

The substances D-Phe-pipecolyl-Arg- $p$-nitroanilide (D-Phe-PipArg-pNA; S-2238) and D-Val-Leu-Arg-p-nitroanilide (D-Val-LeuArg-pNA; S-2266) were from Kabi (Molndal, Sweden) whereas tosyl-Gly-Pro-Lys-p-nitroanilide (tos-Gly-Pro-Arg-pNA; Chromozym-PL) was from Boehringer-Mannheim, FRG). $r-$ HV2-Lys ${ }^{47}$ was purchased from Pentapharm (Basel, Switzerland) and rHV1 was a gift from Ciba-Geigy (Basel, Switzerland). Human $\alpha$-thrombin and $\gamma$-thrombin were prepared as described previously (Stone and Hofsteenge, 1986; Braun et al. 1988b) and were fully active as determined by active site titration with 4-methylumbelliferyl $p$-guanidinobenzoate (Jameson 
et al., 1973). Amino acid sequence analysis (Hewick et al., 1981) and polyacrylamide gel electrophoresis (Laemmli, 1970) indicated that the $\alpha$-thrombin used was pure and free from degraded forms. In addition, human $\alpha$-thrombin was obtained from Sigma (St Louis, MO). PAGE (Laemmli, 1970), followed by densiometric scanning of this thrombin preparation (4200 NIH units/mg; Catalogue no. T6759; Lot 114F-9461), indicated that it contained a substantial amount $(\geq 20 \%)$ of degraded forms of thrombin $\beta$ and $\gamma$.

\section{Amidolytic assay of thrombin}

Assays were performed at $37^{\circ} \mathrm{C}$ in buffers containing $0.1 \%$ poly(ethylene glycol) $M_{r} 6000$ as previously described (Stone and Hofsteenge, 1986). Three different buffer systems were used.

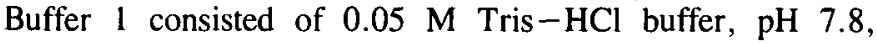
containing $0.1 \mathrm{M} \mathrm{NaCl}$. An ionic strength of $0.125 \mathrm{M}$ can be calculated for this buffer (Ellis and Morrison, 1982). Buffer 2 was the buffer used by Degryse et al. (1989) and contained $0.05 \mathrm{M}$ piperazine- $\mathrm{N}^{\prime}, \mathrm{N}$-bis-2-ethanesulphonic acid (PIPES) $\mathrm{NaOH}, \mathrm{pH} 7.9$, and $0.18 \mathrm{M} \mathrm{NaCl}$ with a calculated ionic strength of $0.327 \mathrm{M}$. Buffer 3 consisted of $0.05 \mathrm{M}$ Tris $-\mathrm{HCl}$, $\mathrm{pH} 7.8$ and $0.3 \mathrm{M} \mathrm{NaCl}$ and had an ionic strength of $0.325 \mathrm{M}$. The type and concentration of substrate used and the concentration of thrombin varied between the experiments.

\section{Data analysis}

Determination of the concentrations of the hirudin variants. The concentration of active hirudin molecules was determined by titration of $1.0 \mathrm{nM}$ thrombin in Buffer 1 containing $200 \mu \mathrm{M}$ D$\mathrm{Val}$-Leu-Arg-pNA. The dependence of the steady-state velocity on the amount of hirudin present in the assay could be described by equation (1) (Stone and Hofsteenge, 1986):

$$
\left.v_{\mathrm{s}}=\frac{v_{0}}{2 E_{\mathrm{t}}}\left\{\left[K_{l^{\prime}}+\alpha l_{\alpha}-E_{\mathrm{t}}\right)^{2}+4 E_{\mathrm{t}} K_{l^{\prime}}\right]^{1 / 2}-\left(K_{I^{\prime}}+\alpha I_{\alpha}-E_{\mathrm{t}}\right)\right\}(1)
$$

where $v_{\mathrm{s}}$ is the observed steady-state velocity, $v_{0}$ is the steadystate velocity in the absence of hirudin, $E_{\mathrm{t}}$ is the total molar enzyme concentration, $K_{\mathrm{l}^{\prime}}$ is the apparent inhibition constant, $I_{\alpha}$ is $\mu \mathrm{l} / \mathrm{ml}$ of hirudin added and $\alpha$ is the molar concentration of $1.0 \mu \mathrm{l} / \mathrm{ml}$ of hirudin. Analysis of the data yielded values for $\alpha$ that could be used to calculate the concentrations of hirudin in the stock solutions.

Determination of kinetic parameters. The inhibition of thrombin by hirudin can be represented by the following scheme:

$$
\text { thrombin }+ \text { hirudin } \underset{k_{2}}{\stackrel{k_{1}}{\rightleftharpoons}} \text { thrombin-hirudin }
$$

The dissociation constant $\left(K_{\mathrm{I}}\right)$ for the thrombin-hirudin complex can be related to the association $\left(k_{1}\right)$ and dissociation $\left(k_{2}\right)$ rate constants by the expression $K_{1}=k_{2} / k_{1}$. The kinetic parameters for the inhibition of human $\alpha$-thrombin by rHV2-Lys ${ }^{47}$ and rHV1 were determined under several different experimental conditions. Under all conditions used, hirudin acted as a slow, tight-binding inhibitor of thrombin and the data were fitted to equation 4 of Stone and Hofsteenge (1986) by nonlinear regression. These analyses yielded values for the apparent dissociation constant $\left(K_{\mathrm{l}^{\prime}}\right)$ and apparent association rate constant $\left(k_{1}\right)$. With the substrate tos-Gly-Pro-Lys-pNA, a background rate of hydrolysis was observed in the absence of enzyme. This rate was dependent on the substrate concentration and equal to $0.035 \mu \mathrm{M} / \mathrm{min} / \mathrm{mM}$ substrate. The data were corrected for this background rate before analysis. The rate of hydrolysis of $D-$ Phe-Pip-Arg-pNA in the absence of thrombin was negligible.
The dependence of the value of $K_{\mathrm{I}^{\prime}}$ on the concentration of substrate for a competitive inhibitor is given by equation 2 :

$$
K_{\mathrm{l}^{\prime}}=K_{\mathrm{l}}\left(1+S / K_{\mathrm{m}}\right)
$$

where $S$ is the substrate concentration and $K_{\mathrm{m}}$ is its Michaelis constant. This equation can be used to calculate $K_{\mathrm{I}}$ from the observed value of $K_{\mathrm{I}^{\prime}}$.

Stimulation of the effect of contamination by $\gamma$-thrombin. It has been shown previously that hirudin has a much lower affinity for human $\gamma$-thrombin than for $\alpha$-thrombin (Landis et al., 1978; Stone et al., 1987). The effect of contamination by $\gamma$-thrombin was simulated according to equation 3 :

$$
v_{\mathrm{s}}=v_{\mathrm{s} \alpha}+v_{\mathrm{s} \gamma}
$$

where $v_{\mathrm{s} \alpha}$ and $v_{\mathrm{s} \gamma}$ are the contributions to the observed velocity $\left(v_{\mathrm{s}}\right)$ made by the $\alpha$ - and $\gamma$-thrombin in the preparation respectively. The values of $v_{\mathrm{s} \alpha}$ and $v_{\mathrm{s} \gamma}$ are given by:

$$
\begin{aligned}
& \left.v_{s \alpha}=\frac{v_{0}}{2 E_{\alpha}}\left\{\left[K_{\mathrm{I} \alpha^{\prime}}+I_{\mathrm{t}}-E_{\alpha}\right)^{2}+4 K_{\mathrm{I} \alpha^{\prime}} E_{\alpha}\right]^{1 / 2}-\left(K_{\mathrm{I} \alpha^{\prime}}+I_{\mathrm{t}}-E_{\alpha}\right)\right\} \\
& \left.v_{\mathrm{s} \gamma}=\frac{v_{0}}{2 E_{\gamma}}\left\{\left[K_{\mathrm{I} \gamma^{\prime}}+I_{\mathrm{t}}-E_{\gamma}\right)^{2}+4 K_{\mathrm{I} \gamma^{\prime}} E_{\gamma}\right]^{1 / 2}-\left(K_{\mathrm{I} \gamma^{\prime}}+I_{\mathrm{t}}-E_{\gamma}\right)\right\}
\end{aligned}
$$

where $E_{\alpha}$ and $E_{\gamma}$ are the concentrations of $\alpha$ - and $\gamma$-thrombin respectively, and $K_{\mathrm{I} \alpha^{\prime}}$ and $K_{\mathrm{I} \gamma^{\prime}}$ are the apparent dissociation constants for hirudin with $\alpha$ - and $\gamma$-thrombin. The values $K_{\mathrm{I} \alpha^{\prime}}$ and $K_{\mathrm{I} \gamma^{\prime}}$ for these simulations can be calculated at different substrate concentrations by using equation (2). Estimates for $K_{\mathrm{I} \alpha}, K_{\mathrm{I} \gamma}$ and the $K_{\mathrm{m}}$ values for $\alpha$ - and $\gamma$-thrombin with the substrate are required for these calculations. The values of $K_{\mathrm{m}}$ to be used in these calculations were determined as described by Hofsteenge et al. (1986) to be $105 \pm 9 \mu \mathrm{M}$ and $98 \pm 2 \mu \mathrm{M}$ for the substrate tos-Gly-Pro-Lys-pNA with $\alpha$ - and $\gamma$-thrombin respectively. The value of the $K_{\mathrm{I} \alpha}$ was determined to be $2.3 \mathrm{pM}$ (Table I) under the conditions used by Degryse et al. (1989). The value of $K_{\mathrm{I} \gamma}$ was determined from the observed inhibition of $\gamma$-thrombin by rHV2-Lys ${ }^{47}$ under the same conditions. The data were fitted to the Dixon equation (Segel, 1975) and a value of $75 \pm 3 \mathrm{nM}$ for $K_{\mathrm{I} \gamma}$ was calculated after correcting for the concentration of substrate according to equation (2).

Using the above constants, values for $K_{\mathrm{I} \alpha^{\prime}}$ and $K_{\mathrm{I} \gamma^{\prime}}$ were calculated at a number of different substrate concentrations and inhibition data were simulated with different ratios of $\alpha$ - to $\gamma$ thrombin under the conditions similar to those used by Degryse et al. (1989): the total enzyme concentration was maintained at $4.5 \mathrm{nM}$ and the concentration of $\mathrm{rHV} 2-\mathrm{Lys}^{47}$ was varied from 0 to $6 \mathrm{nM}$ (10 points). For each substrate concentration, 10 sets of data were simulated according to equation 3 . A normally distributed random error with a standard deviation of $2 \%$ of the theoretical value was introduced into the simulated data (Pollard, 1977). The 10 sets of simulated data were analysed according to equation (1) with $E_{\mathrm{t}}=E_{\alpha}+E_{\gamma}$ and 10 estimates for $K_{\mathrm{l}}$, were obtained. The weighted mean estimate of $K_{\mathrm{I}^{\prime}}$ was calculated for each substrate concentration.

\section{Results}

The hirudin variant $r H V 2-L y s^{47}$ is a competitive inhibitor of human $\alpha$-thrombin

The kinetic mechanism of the inhibition of human $\alpha$-thrombin by $\mathrm{rHV}^{2}-\mathrm{Lys}^{47}$ was studied under the conditions used by 


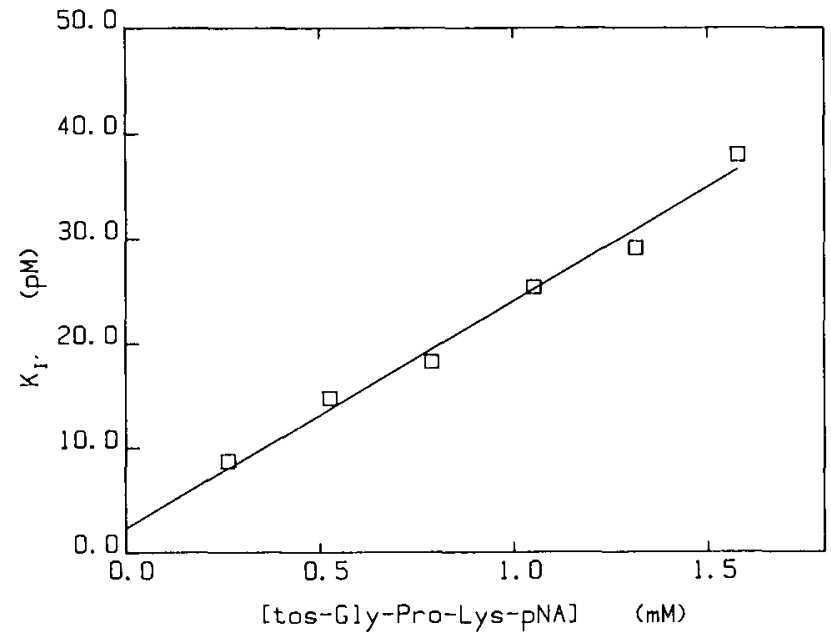

Fig. 1. Dependence of the apparent dissociation constant $\left(K_{\mathrm{I}^{\prime}}\right)$ for rHV2-Lys ${ }^{47}$ on the concentration of the substrate tos-Gly-Pro-Lys-pNA. Assays were performed in PIPES-NaOH buffer (Buffer 2) and the data analysed as described in Materials and methods to yıeld estimates for $K_{\mathrm{I}^{\prime}}$ at the indicated substrate concentrations. These estimates were weighted according to the squared inverse of their standard errors and fitted to equation 2. The line drawn depicts the result of this fitting. For this analysis, the value of $K_{\mathrm{m}}$ in equation (2) was fixed at the previously determined value of $105 \mu \mathrm{M}$

Degryse et al. (1989), i.e. in PIPES- NaOH buffer (pH 7.9) with an ionic strength of $0.33 \mathrm{M}$ (Buffer 2) with the substrate tosGly-Pro-Lys-pNA. Values for the apparent dissociation constant $\left(K_{\mathrm{I}^{\prime}}\right)$ were determined at a particular substrate concentration by varying the concentration of rHV2-Lys ${ }^{47}$ from 56 to $280 \mathrm{pM}$ with a fixed concentration of $200 \mathrm{pM} \alpha$-thrombin. Under these conditions, rHV2-Lys ${ }^{47}$ acted as a slow, tight-binding inhibitor (data not shown) and analysis of progress-curve data yielded values for $K_{I^{\prime}}$ and for the apparent association rate constant $\left(k_{1^{\prime}}\right)$. The values of $K_{\mathrm{l}}$, showed a linear dependence on the concentration of the substrate as would be expected from equation (2) for a competitive inhibitor (Figure 1). A value of $105 \pm 9$ $\mu \mathrm{M}$ was determined for the $K_{\mathrm{m}}$ of tos-Gly-Pro-Lys-pNA from initial-velocity studies. The value of $K_{\mathrm{m}}$ in equation (2) was fixed at this value and the data of Figure 1 fitted by weighted linear regression to this equation. The line drawn in Figure 1 represents the result of this analysis and it can be seen that the data fit well to the equation describing competitive inhibition. The value for $K_{\mathrm{I}}$ obtained from this analysis was $2.29 \pm$ $0.05 \mathrm{pM}$ (Table I).

The estimate of $k_{1}$, did not vary greatly over the substrate range tested. Similar results were obtained previously with native hirudin variant-1 (Stone and Hofsteenge, 1986). The weighted average of the six determinations of $k_{1}$, was $(3.6 \pm 0.1) \times 10^{7} /$ $\mathrm{M} / \mathrm{s}$ and it can be assumed that this value approximates the true value of the association rate constant $k_{1}$ (Table I).

In order to confirm the competitive nature of the inhibition by $\mathrm{rHV} 2-\mathrm{Lys}^{47}$, the substrate-dependence of the value of $K_{\mathrm{I}^{\prime}}$ was determined with another substrate. The results obtained with the substrate D-Phe-Pip-Arg-pNA are shown in Figure 2; a similar linear dependence was observed. The concentrations of $\alpha$ thrombin and rHV2-Lys ${ }^{47}$ used to obtain the data presented in Figure 2 were also different; the enzyme was present at a concentration of $20 \mathrm{pM}$ while rHV2-Lys ${ }^{47}$ was varied from 61 to $306 \mathrm{pM}$. An estimate of $4.2 \pm 0.2 \mu \mathrm{M}$ was determined from initial-velocity studies for the $K_{\mathrm{m}}$ of D-Phe-Pip-Arg-pNA in the PIPES - NaOH buffer used and the value of $K_{\mathrm{m}}$ in equation (2) was fixed at this value for the analysis of the data of Figure 2.
Table I. Kinetic parameters for the interaction of rHV2-Lys ${ }^{47}$ and rHV1 with human $\alpha$-thrombin

\begin{tabular}{|c|c|c|c|}
\hline \multicolumn{2}{|c|}{ Experimental conditions } & \multicolumn{2}{|c|}{ Kınetic parameters } \\
\hline Buffer & Substrate & $\begin{array}{l}k_{1} \times 10^{-7} \\
(/ \mathrm{m} / \mathrm{s})\end{array}$ & $\begin{array}{l}K_{\mathrm{I}} \\
(\mathrm{pM})\end{array}$ \\
\hline \multicolumn{4}{|l|}{ rHV2-Lys ${ }^{47}$} \\
\hline $\begin{array}{l}\text { PIPES-NaOH } \\
(I=0.33 \mathrm{M})\end{array}$ & tos-Gly-Pro-Lys-pNA & $3.61 \pm 0.07$ & $2.29 \pm 0.05$ \\
\hline $\begin{array}{l}\text { PIPES-NaOH } \\
(I=033 \mathrm{M})\end{array}$ & D-Phe-Pip-Arg-pNA & $2.78 \pm 0.03$ & $235 \pm 0.02$ \\
\hline $\begin{array}{l}\text { Tris }-\mathrm{HCl}^{\mathrm{c}} \\
(I=0.33 \mathrm{M})\end{array}$ & D-Phe-Pip-Arg-pNA & $2.51 \pm 0.11$ & $2.47 \pm 0.04$ \\
\hline $\begin{array}{l}\text { Tris }-\mathrm{HCl} \\
(I=0.125 \mathrm{M})\end{array}$ & D-Phe-Plp-Arg-pNA & $11.3 \pm 0.64$ & $0.364 \pm 0.015$ \\
\hline \multicolumn{4}{|l|}{ rHV1 } \\
\hline $\begin{array}{l}\text { Tris }-\mathrm{HCl} \\
(I=033 \mathrm{M})\end{array}$ & D-Phe-Pip-Arg-pNA & $3.25 \pm 0.16$ & $0.991 \pm 0.030$ \\
\hline $\begin{array}{l}\text { Tris }-\mathrm{HCl}^{\mathrm{d}} \\
(I=0.125 \mathrm{M})\end{array}$ & D-Phe-Pip-Arg-pNA & $13.7 \pm 0.3$ & $0.231 \pm 0.006$ \\
\hline
\end{tabular}

Values of $K_{1}$ and $k_{1}$ were calculated from apparent values as described in the text. The $K_{\mathrm{m}}$ values for D-Phe-Pip-Arg-pNA that were used in the calculations were $36,4.2$ and $30 \mu \mathrm{M}$ for Buffers 1,2 and 3 respectively. aThese values were calculated from the data of Figure 1.

${ }^{b}$ These values were calculated from the data of Figure 2.

'These values represent the weighted mean of two determinations.

dFrom Braun et al. (1988a).

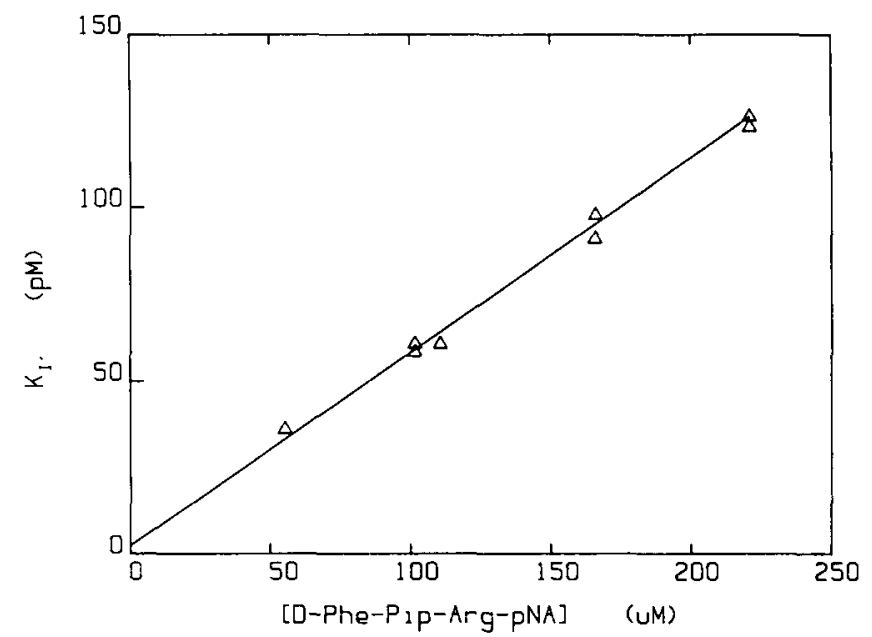

Fig. 2. Dependence of the apparent dissociation constant $\left(K_{1}\right)$ for rHV2-Lys ${ }^{47}$ on the concentration of the substrate D-Phe-Pip-Arg-pNA. Assays were performed in PIPES- $\mathrm{NaOH}$ buffer (Buffer 2) and the data analysed as described in Materials and methods to yield estimates for $K_{1}$, at different substrate concentrations. These estimates were fitted by weighted linear regression to equation 2 as described in the legend to Figure 1 with the value of $K_{\mathrm{m}}$ set at $4.2 \mu \mathrm{M}$ The line drawn depicts the fit of the data to equation (2).

This analysis yielded a value of $2.35 \pm 0.02 \mathrm{pM}$ for $K_{\mathrm{l}}$. The good fit of the data to equation (2) shown in Figure 2 indicates that the competitive model, which this equation describes, is an appropriate one for the interaction of rHV2-Lys ${ }^{47}$ with $\alpha$ thrombin. Moreover, the good agreement between the values for $K_{1}$ estimated from the data of Figures 1 and 2 confirms this competitive model.

As was observed with the substrate tos-Gly-Pro-Lys-pNA, the value of $k_{1}$, did not vary with the concentration of D-Phe-PipArg-pNA and the value for $k_{1}$ given in Table I represents the weighted mean of the eight determinations of $k_{1}$. 

Comparison of the inhibitory properties of the hirudin
variants $r H V 1$ and $r H V 2-L y s$

For the comparison of the inhibitory properties of rHV2-Lys ${ }^{47}$ and $\mathrm{rHV} 1, \mathrm{~T}$ ris $-\mathrm{HCl}$ buffers have been used. [PIPES $-\mathrm{NaOH}$ buffer was used in the above studies so that the results would
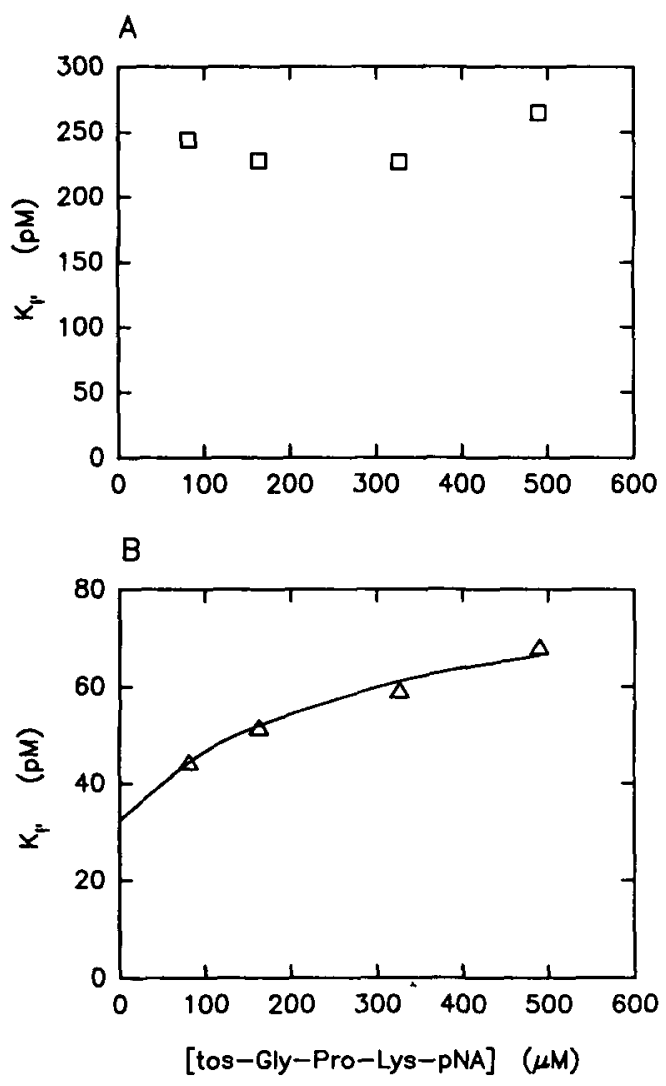

Fig. 3. Dependence of the apparent dissociation constant $\left(K_{\mathrm{I}^{\prime}}\right)$ for rHV2-Lys ${ }^{47}$ with different forms of thrombin on the concentration of the substrate tos-Gly-Pro-Lys-pNA. Assays were performed in PIPES- $\mathrm{NaOH}$ buffer (Buffer 2) with thrombin from Sigma (A) or $\alpha$-thrombin containing $4 \% \gamma$-thrombin (B) and the data analysed according to equation (1) to yleld estimates for $K_{\mathrm{l}}$ at the indicated substrate concentrations. For the data in (B) the estimates of $K_{\mathrm{I}}$, were weighted according to the squared inverse of their standard errors and fitted to equation (6). The line drawn depicts the result of this fitting with the value of $K_{\mathrm{m}}$ fixed at $105 \mu \mathrm{M}$. be directly comparable with those of Degryse et al. (1989). However, Tris - $\mathrm{HCl}$ buffers have a much better buffering capacity at the $\mathrm{pH}$ values used (Ellis and Morrison, 1982).] In Tris $-\mathrm{HCl}$ buffer with an ionic strength of $0.325 \mathrm{M}$ (Buffer 3), a $K_{\mathrm{I}}$ value of $2.47 \pm 0.04 \mathrm{pM}$ was determined for rHV2-Lys ${ }^{47}$ (Table I). This value agrees well with those determined in the PIPES-NaOH buffer (Buffer 2) which has about the same ionic strength. Under the same conditions, a value of $0.99 \pm 0.03 \mathrm{pM}$ was determined for the $K_{\mathrm{I}}$ of rHVl (Table I). The association rate constants $\left(k_{1}\right)$ for rHV1 and rHV2-Lys ${ }^{47}$ were about equal and, thus, the increase in the affinity observed with rHVl can be attributed to a lower rate of dissociation of rHVI from the hirudin-thrombin complex (Table I).

In Tris- $\mathrm{HCl}$ buffer with an ionic strength of $0.125 \mathrm{M}$ (Buffer 1), the difference between the $K_{\mathrm{I}}$ values for $\mathrm{rHVl}$ and rHV2-Lys ${ }^{47}$ was slightly less; values of $0.231 \pm 0.006$ and $0.364 \pm 0.015 \mathrm{pM}$ were observed for rHV1 and rHV2-Lys ${ }^{47}$ respectively (Table I). Once again, the $k_{1}$ values for both forms were about equal. The values of $k_{1}$ and $K_{\mathrm{I}}$ for both $\mathrm{rHVl}$ and rHV2-Lys ${ }^{47}$ were lower at the lower ionic strength in accordance with previous observations (Stone and Hofsteenge, 1986; Stone et al., 1989).

Effect of the presence of $\gamma$-thrombin in preparations used for kinetics

The results shown in Figures $I$ and 2 contrast with those obtained by Degryse et al. (1989), where a hyperbolic dependence of $K_{\mathrm{I}^{\prime}}$ on substrate concentration was observed. Such a hyperbolic dependence suggests a noncompetitive mechanism for the inhibition of thrombin by hirudin. It seemed possible that the difference between the results obtained by Degryse et al. (1989) and those of the present study could be due to the different forms of thrombin used in the two studies. In order to test this possibility, $K_{\mathrm{l}^{\prime}}$ values were determined under the conditions used by Degryse et al. (1989) with commercial human $\alpha$ thrombin from the same source; i.e. Buffer 2 and tos-Gly-ProLys-pNA with $4.5 \mathrm{nM}$ human thrombin from Sigma and 0-6 nM rHV2-Lys ${ }^{47}$. The substrate dependence of the $K_{\mathrm{I}^{\prime}}$ value determined under these conditions is shown in Figure 3(A). The values of $K_{\mathrm{I}^{\prime}}$ determined using this source of thrombin were much higher than the values at corresponding substrate concentrations shown in Figure 1. Moreover, the almost negligible substrate dependence of the $K_{\mathrm{I}^{\prime}}$ values suggests

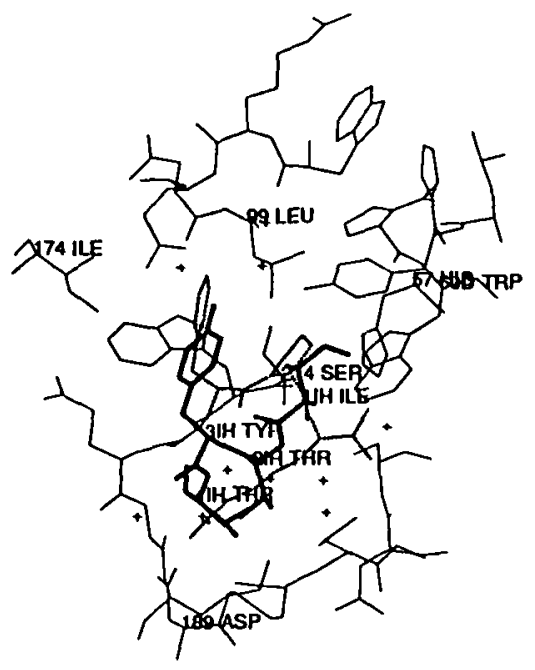

Fig. 4. Comparison of the binding of rHV2-Lys ${ }^{47}$ and D-Phe-Pro- $\mathrm{ArgCH}_{2}$ to the active-site of thrombin. The binding of rHV2-Lys ${ }^{47}$ (thick lines; from Rydel

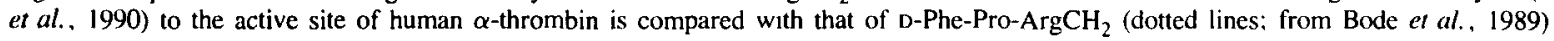


uncompetitive inhibition. The results of Figure 3 also differ somewhat from those obtained by Degryse et al. (1989) suggesting that there may be some batch-to-batch variation in the kinetic behaviour of commercial thrombin preparations. Human $\beta$ - and $\gamma$-thrombin can arise by autolytic degradation of $\alpha$-thrombin (Fenton et al., 1977a,b) and it has been shown previously that $\beta$ - and $\gamma$-thrombin have a much lower affinity for hirudin than $\alpha$-thrombin (Landis et al., 1978; Stone et al., 1987). PAGE of the Sigma thrombin used in the present study indicated that it contained $>20 \%$ degraded thrombin. The effect of contamination with $\gamma$-thrombin was determined experimentally by adding $\gamma$-thrombin to pure $\alpha$-thrombin. The results obtained when $\alpha$-thrombin was contaminated with $4 \% \gamma$-thrombin are shown in Figure 3(B). These results are similar to those obtained by Degryse et al. (1989); the hyperbolic dependence of $K_{\mathrm{I}^{\prime}}$ on the substrate concentration suggests noncompetitive inhibition. Equation (6) describes the dependence of $K_{I^{\prime}}$ on substrate concentration for a noncompetitive inhibitor:

$$
K_{\mathrm{I}^{\prime}}=\frac{K_{\mathrm{m}}+\mathrm{S}}{K_{\mathrm{m}} / K_{\mathrm{ls}}+S / K_{11}}
$$

where $K_{\mathrm{is}}$ and $K_{\mathrm{u}}$ represent the dissociation constant of the inhibitor from the free enzyme and the enzyme-substrate complex respectively. Weighted nonlinear regression analysis of the data of Figure 3(B) according to this equation yielded values of $32 \pm 1$ and $86 \pm 4 \mathrm{pM}$ for $K_{\mathrm{ts}}$ and $K_{\mathrm{II}}$ respectively. Degryse et al. (1989) analysed their data according to equation (6) and obtained values of 14 and $129 \mathrm{pM}$ for $K_{\text {is }}$ and $K_{\mathrm{ii}}$ respectively.

An alternative explanation for the different kinetic behaviour observed with commercial thrombin is that it contains proteases other than thrombin that are not inhibited by hirudin. Hirudin demonstrates an absolute specificity for thrombin. All other proteases so far examined are not inhibited even with micromolar concentrations of hirudin (Wallis, 1988), while even the degraded forms of thrombin will be completely inhibited by micromolar concentrations. Under the conditions of the assay, rHV1 has $K_{\mathrm{I}}$ values of $49 \mathrm{pM}$ and $85 \mathrm{nM}$ with $\beta$ - and $\gamma$-thrombin respectively (S.R.Stone and J.Hofsteenge, unpublished results). The preparation of thrombin from Sigma used in this study was completely inhibited by $1.6 \mu \mathrm{M}$ rHV 1 and, thus, a contamination by other proteases is not the cause of the anomalous kinetic behaviour observed with this preparation of thrombin.

The effect of contamination with degraded forms of thrombin, specifically $\gamma$-thrombin, was further investigated by using data simulation techniques. The $K_{\mathrm{I}}$ value for $\mathrm{rHV}^{2-\mathrm{Lys}^{47}}$ with $\gamma$ thrombin required for these simulations was determined to be $75 \pm 3 \mathrm{nM}$ which is $10^{4}$-fold higher than that observed with $\alpha$-thrombin. Using this value, data were simulated for various percentage contaminations with $\gamma$-thrombin as described in Materials and methods. Ten sets of data were simulated for several substrate concentrations and these data were analysed according to equation 1 . The results obtained depended markedly on the percentage contamination by $\gamma$-thrombin, the total enzyme concentration and the range of hirudin concentrations used. The deviation of the results from those expected for a competitive inhibitor was smaller with lower contaminations of $\gamma$-thrombin, with lower total enzyme concentrations and with ranges of inhibitor concentrations that did not greatly exceed the concentration of $\alpha$-thrombin. Higher levels of contamination $(>10 \%)$ together with high enzyme concentrations $(>1 \mathrm{nM})$ and inhibitor to enzyme ratios $(>2)$ led to data that suggested uncompetitive inhibition and were similar to those shown in Figure $3(A)$. Low contaminations of $\gamma$-thrombin $(2-5 \%)$ yielded data that were consistent with noncompetitive inhibition. The data of Degryse et al. (1989) were best simulated by assuming a contamination of $2 \% \gamma$-thrombin. Simulations of the effect of a contamination with $\beta$-thrombin, assuming a $K_{\mathrm{I}}$ value of $50 \mathrm{pM}$ for $\mathrm{rHV}_{2}-\mathrm{Lys}^{47}$ with this form (see above), indicated that preparations with a relatively large contamination $(10 \%)$ of $\beta$ thrombin should still yield data consistent with competitive inhibition but the observed values of the $K_{\mathrm{l}}$, would be increased.

\section{Discussion}

The results presented here indicate that $\mathrm{rHV}^{-}-\mathrm{Lys}^{47}$ is a competitive inhibitor of human $\alpha$-thrombin. The competitive nature of the inhibition was demonstrated with two substrates (Figures 1 and 2). Similar results have been obtained previously for native hirudin variant-1 (Stone and Hofsteenge, 1986). These results, however, contrast with those of Degryse et al. (1989); these workers suggested a noncompetitive mechanism for the inhibition of human $\alpha$-thrombin by rHV2-Lys ${ }^{47}$. The discrepancy between the two studies is due probably to the different thrombin preparations used, as indicated by the data presented in Figure 3. The data obtained in the present study with a commercial thrombin preparation were also not consistent with competitive inhibition (Figure $3 \mathrm{~A}$ ). The kinetic behaviour of the commercial preparation is probably due to the presence of degraded forms of thrombin $(\beta$ and $\gamma)$. It was shown experimentally that a slight contamination of $\alpha$-thrombin by $\gamma$-thrombin (4\%) can yield data suggesting noncompetitive inhibition (Figure 3B). $\gamma$-Thrombin is a degraded form of $\alpha$-thrombin that can arise through autolysis (Fenton et al., 1977a,b). This form of thrombin has a much reduced activity with fibrinogen (Lewis et al., 1987) and its affinity for hirudin is likewise greatly diminished (Landis et al., 1978; Stone et al. . 1987). Simulations of the effect of contaminating $\gamma$-thrombin on the determined $K_{\mathrm{l}}$, value indicate that a contamination as low as $2 \%$ could yield data consistent with a noncompetitive mechanism. Larger contaminations would yield data that suggest uncompetitive inhibition. These results illustrate the importance of using pure $\alpha$-thrombin preparations for the determination of the kinetics of inhibition with hirudin.

The recently determined crystal structures of thrombin-hirudin complexes also indicate that hirudin inhibits thrombin by a competitive mechanism (Grütter et al., 1990; Rydel et al., 1990). The binding of rHV2-Lys ${ }^{47}$ (bold structure) and the substratelike inactivator D-Phe-Pro-Arg- $\mathrm{CH}_{2}$ (dotted structure) to the active site of thrombin are contrasted in Figure 4 . From this figure, it is obvious that Mlel and Tyr3 of hirudin occupy the $S_{2}$ and $S_{3}$ sites of the substrate (nomenclature of Schechter and Berger, 1967) and, thus, the binding of a tripeptidyl substrate and hirudin would be mutually exclusive. In other words, the structure illustrated in Figure 4 indicates that hirudin must be a competitive inhibitor with respect to tripeptidyl $p$-nitroanilide substrates as has been observed in the present study.

Although hirudin is a competitive inhibitor with respect to tripeptidyl $p$-nitroanilide substrates, it also utilizes binding sites on thrombin that are distant from the active site. The X-ray crystal structures of thrombin-hirudin complexes show that the $\mathrm{C}$ terminal tail of hirudin makes numerous electrostatic and hydrophobic contacts with a surface groove of thrombin (Grütter et al., 1990; Rydel et al., 1990). It had been shown previously that fragments of hirudin consisting of the C-terminal tail were capable of binding to thrombin (Mao et al., 1988; Krstenansky and Mao, 1987; Maraganore et al., 1989). Indeed, hirudin itself is capable of binding to thrombin when its active site is occupied 
by a tripeptidyl inhibitor (Stone et al., 1987). The affinity of thrombin for the C-terminal fragments of hirudin is, however, about seven orders of magnitude lower than its affinity for hirudin (Krstenansky and Mao, 1987; Braun et al., 1988a). Moreover, the binding of the C-terminal fragment of hirudin to thrombin does not inhibit the activity of thrombin with tripeptidyl substrates. Indeed, the binding of C-terminal fragments of hirudin to thrombin stimulates its activity with respect to small substrates (Dennis et al., 1990; Naski et al., 1990).

The data presented in Table I indicate that $\mathrm{rHVI}$ and rHV2-Lys ${ }^{47}$ have basically the same kinetic parameters for the inhibition of human $\alpha$-thrombin; rHV1 has a slightly higher affinity. The primary structures of rHV2-Lys ${ }^{47}$ and rHV1 differ from each other in eight of the 65 residues in the polypeptide chain. Four of the differences between the two hirudins occur in residues that do not make any contacts with thrombin (Asn33, Lys35, Gly36 and Asn53 of rHV2-Lys ${ }^{47}$; Rydel et al., 1990). The small difference in affinity between the two forms may be due to differences in interactions between thrombin and one or more of the other altered residues (Ile1, Thr2, Lys24 and Glu49 of $\mathrm{rHV}^{-\mathrm{Lys}^{47}}{ }^{4}$. Considering the similarity of the kinetic parameters for rHVI and rHV2-Lys ${ }^{47}$, whose sequences are as dissimilar as any two hirudin variants (Scharf et al., 1989), it seems unlikely that the previously observed large variation in dissociation constants is due to differences in the hirudin forms used. Differences in reaction conditions, thrombin preparations and/or methods of data analysis seem more likely to be the cause of these discrepancies.

\section{Acknowledgements}

We thank members of our laboratory and $\mathrm{Dr}$ W.Bode for their helpful discussions and Drs A.Tulınsky and W.Bode for providing Figure 4.

\section{References}

Bagdy,D., Barabas,E., Graf,L., Peterson,T.E. and Magnusson,S. (1976) Methods Enzymol., 45, 669-678.

Bergmann,C., Dodt,J., Köhler,S., Fink,E. and Gassen,H.G. (1986) Bıol. Chem. Hoppe-Seyler, 367, 731-740.

Bode,W.. Mayr,I., Baumann,U., Huber,R , Stone,S.R. and Hofsteenge,J. (1989) $E M B O \mathrm{~J}, \mathrm{8}, 3467-3475$.

Braun.P.J., Dennis.S., Hofsteenge.J. and Stone,S.R. (1988a) Biochemistry, 27, $6517-6522$

Braun,P.J., Hofsteenge,J., Chang,J.-Y. and Stone.S.R. (1988b) Thromb. Res., 50, 273-283.

Clore,G.M., Sukumaran,D.K., Nilges.M., Zarbock,J. and Gronenborn,A.M. (1987) EMBO J., 6, 529-537.

Degryse,E., Acker,M., Defreyn,G., Bernat.A., Maffrand.J.P., Roitsch,C. and Courtney.M. (1989) Protein Engng, 2, 459-465.

Dennıs,S. Wallace.A.. Hofsteenge.J. and Stone.S.R. (1990) Eur J. Biochem. $188,61-66$.

Dodt,J., Müller,H., Seemüller,U. and Chang,J.-Y (1984) FEBS Lett., 165 $180-183$.

Dodt,J., Machleidt.N., Seemüller,U., Maschler.R. and Fritz.H. (1986) Biol. Chem. Hoppe-Seyler, 367, 803-811

Dodt,J., Köhler.S. and Baicı,A. (1988) FEBS Lett., 229, 87-90.

Dodt,J., Köhler,S , Schmitz,T. and W.lhelm,B. (1990) J. Biol. Chem., 265, $713-714$.

Ellis,K.J. and Morrison,J.F. (1982) Methods Enzymol. . 87, 405-426.

Fenton,J.W.,II. Fasco,M.J., Stackrow,A.B., Aronson,D.L., Young,A M. and Finlayson,J.S. (1977a) J. Biol. Chem., 252, 3587-3598.

Fenton,J.W.,II, Landis,B.H., Walz,D.A. and Finlayson.J.S. (1977b) In Lundblad, R.L., Fenton,J.W.,II and Mann,K.G. (eds), Chemistry and Biology of Thrombin. Ann Arbor Science Publishers, Ann Arbor, pp. 43-70.

Fenton,J.W.,II, Landis,B.H., Walz,D.A., Bing,D.H., Feınmann.R.D., Zabinski,M P., Sonder,S.A.. Berliner.L.J. and Finlayson.J.S. (1979) In Bing,D.H. (ed), The Chemistry and Physiology of Human Plasma Proteins. Pergamon, New York, pp. 151-183.

Folkers,P.J.M., Clore,G.M., Driscoll,P.C., Dodt.J., Köhler.S. and Gronenborn.A. (1989) Biochemistry, 28, 2601-2617
Fortkamp,E., Rieger,M., Heisterberg-Moutses,G.. Schweitzer.S. and Sommer.R. (1986) DNA, 5, 511-517.

Grütter.M.G., Prestle,J.P., Rahuel,J., Grossenbacher,H., Bode,W., Hofsteenge.J and Stone.S.R (1990) EMBO J.. 9. 2361-2365

Haruyama,H and Wuthrich,K (1989) Biochemistry, 28, 430I-4312.

Harvey,R.P., Degryse,E., Stefani,L., Schamber,F., Cazenave,J.-P.. Courtney.M., Tolstoshev,P. and Lecocq.J.-P. (1986) Proc Natl Acad. Sci. USA, 83, $1084-1088$.

Hewick,R.M., Hunkapillar,M.W., Hood,L.E. and Dreyer,W J. (1987) J. Biol. Chem., 256. 7990-7997

Hofsteenge,J., Taguchi,H. and Stone,S.R. (1986) Biochem J., 237, 243-25I.

Jameson,G W., Roberts,D.V., Adams,R.W., Kyle,W.S.A. and Elmore,D.T. (1973) Biochem J., 131, 101-117

Krstenansky,J.L. and Mao,S J.T. (1987) FEBS Lett., 211, 10-16.

Laemmli,U.K. (1970) Nature, 227, 680-685.

Landis,B.H., Zabinski,M.P., Lafleur,G.J.M., Bing,D.H. and Fenton,J.W.,Il (1978) Fed. Proc., Fed. Am. Soc. Exp. Bıol., 37, 1445.

Lewis,S.D., Lorand.L., Fenton,J.W ,Il and Shafer.J.A. (1987) Biochemustry, 26, 7597-7603.

Loison.G, Findel,A., Bernard,S., Nguyen-Juilleret,M., Marquet.M., RichlBellon,N., Carvallo,D., Guerra-Santos,L., Brown,S.W., Courtney,M. Rotssch,C and Lemoine,Y. (1988) Blotechnology, 6, 72-77.

Mao,S.J T., Yates, M.T., Owen.T.J. and Krstenansky,J.L. (1988) Biochemistry. 27, 8170-8173.

Maraganore,J.M., Chao,B., Joseph,M.L., Jablonskı,J. and Ramachandran,K L. (1989) J. Biol Chem., 264, 8692-8698.

Markwardt,F. (1970) Methods Enzymol., 19, 924-932.

Meyhack,B., Hem,J., Rink,H., Zimmermann,W. and Maerki,W. (1987) Thromb. Res., Suppl., 7, 33.

Naskı,M C.. Fenton.J.W.,II, Maraganore,J.M., Olson,S.T. and Shafer.J.A. (1990) J. Biol Chem., 265, 13484-13489.

Pollard.J.H. (1977) A Handbook of Numerical and Statistical Techniques Cambridge University Press, Cambridge, pp. 239-240.

Rydel,T.J., Ravichrandran,K.G., Tullinsky,R., Bode,W., Huber,R., Rotsch.C. and Fenton,J.W.,II (1990) Science, 245, 277-280.

Scharf.M., Engels,J. and Tripier.D. (1989) FEBS Lett., 255, 105-110.

Schechter.I. and Berger,A. (1967) Biochem. Biophys. Res. Commun., 27, $157-162$.

Segel,I.H. (1975) Enzyme Kinetics. Wiley, New York. pp 196-198.

Stone,S.R. and Hofsteenge,J. (1986) Biochemustry, 25, 4622-4628.

Stone,S.R., Braun,P.J and Hofsteenge,J. (1987) Biochemistry, 26, 4617-4624

Stone,S.R . Dennis, S. and Hof steenge,J. (1989) Brochemistry, 28, 6857-6863

Tripier,D. (1988) Folia Haematol, 115. 30-35.

Wallis.R.B. (1988) Trends Pharmacol. Sct, 9, 425-427.

Walsmann.P. and Markwardt.F. (1981) Pharmazie, 36, 633-660

Received on August 9. 1990, revised and accepted on November 5. 1990 